\title{
Article \\ Marker-Assisted Pyramiding of Genes for Multilocular Ovaries, Self-Compatibility, and Clubroot Resistance in Chinese Cabbage (Brassica rapa L. ssp. pekinensis)
}

\author{
Jingyi Zheng ${ }^{1}$, Huicai Zhao ${ }^{1}$, Yingmei Ma ${ }^{1}$, Mingliang Jiang ${ }^{2}$, Zongxiang Zhan ${ }^{1}$, Xiaonan Li ${ }^{1, * \mathbb{D}}$ \\ and Zhongyun Piao ${ }^{1, *}$
}

check for updates

Citation: Zheng, J.; Zhao, H.; Ma, Y.; Jiang, M.; Zhan, Z.; Li, X.; Piao, Z. Marker-Assisted Pyramiding of Genes for Multilocular Ovaries, Self-Compatibility, and Clubroot Resistance in Chinese Cabbage (Brassica rapa L. ssp. pekinensis). Horticulturae 2022, 8, 139. https:// doi.org/10.3390/horticulturae8020139

Academic Editor: Luigi De Bellis

Received: 20 December 2021

Accepted: 30 January 2022

Published: 6 February 2022

Publisher's Note: MDPI stays neutral with regard to jurisdictional claims in published maps and institutional affiliations.

Copyright: (C) 2022 by the authors. Licensee MDPI, Basel, Switzerland. This article is an open access article distributed under the terms and conditions of the Creative Commons Attribution (CC BY) license (https:// creativecommons.org/licenses/by/ $4.0 /)$.
1 College of Horticulture, Shenyang Agricultural University, Shenyang 110866, China; amberz0301@163.com (J.Z.); zjxsbd0126@163.com (H.Z.); mayingmei0126@163.com (Y.M.); zhanzxiang@126.com (Z.Z.)

2 School of Agriculture, Jilin Agricultural Science and Technology College, Jilin 132101, China; jml005@163.com * Correspondence: Gracesleexn@163.com (X.L.); zypiao@syau.edu.cn (Z.P.); Tel.: +86-42-8848-7143 (Z.P.)

\begin{abstract}
Molecular marker-assisted gene pyramiding combined with backcrossing has been widely applied for crop variety improvement. Molecular marker identification could be used in the early stage of breeding to achieve the rapid and effective pyramiding of multiple genes. To create highquality germplasm for Chinese cabbage breeding, multi-gene pyramiding for self-compatibility, multilocular, and clubroot resistance was performed through molecular marker-assisted selection. The results showed that self-compatibility and multilocular traits were controlled by a pair of recessive genes. Two flanking markers, sau_um190 and cun_246a, and marker Teo-1, based on the gene sequence related to multilocular ovaries, were used for multilocular ovary trait selection. Two flanking markers, SCF-6 and SC-12, and marker Sal-SLGI /PK1+PK4, based on the gene sequence, were used for self-compatibility selection. Two flanking markers, TCR74 and TCR79, closely linked to clubroot resistance gene $C R b$, were used as foreground selection markers. Based on Chinese cabbage genomic information, 111 SSR markers covering 10 chromosomes were applied for background selection. After multiple generations of selection, a multi-gene pyramided line from a $\mathrm{BC}_{4} \mathrm{~F}_{2}$ population with self-compatibility, multilocular ovaries, and clubroot resistance was obtained with a high genomic background recovery rate. The improved pyramided line is expected to be utilized as a potential material in further breeding programs.
\end{abstract}

Keywords: Brassica rapa; gene pyramiding; marker-assisted selection

\section{Introduction}

Chinese cabbage (Brassica rapa L. ssp. pekinensis), belonging to the Brassica subspecies of the Brassicaceae family, is widely cultivated in China, Korea, and Japan. At present, most of the common commercial cultivars on the market are first-generation hybrids. However, owing to self-incompatibility, it is difficult to reproduce the parent lines, and the cost of artificial seed production is high. The seed yield of Chinese cabbage is limited, which is influenced by silique-related traits. Additionally, clubroot, as one of the main diseases of cruciferous crops, has severely threatened the production of Chinese cabbage. Breeding clubroot-resistant (CR) varieties is the most effective method for clubroot prevention since physical and biological control methods have limited effects. Therefore, cultivar pyramiding with multilocular silique, self-compatibility, and clubroot resistance would be an ideal resource for Chinese cabbage breeding.

Cruciferous plants, such as Brassica cultivars included in the U's triangle [1], are mostly bilocular plants, including Brassica rapa $(\mathrm{AA}, 2 \mathrm{n}=20)$, Brassica nigra $(\mathrm{BB}, 2 \mathrm{n}=16)$, Brassica oleracea (CC, $2 \mathrm{n}=18$ ), Brassica napus (AACC, $2 \mathrm{n}=38$ ), Brassica juncea (AABB, $2 \mathrm{n}=36)$, and Brassica carinata (BBCC, $2 \mathrm{n}=34)$. However, with the collection and sorting of 
germplasm resources, some silique variation types, such as multilocular rapeseed, have been discovered. Among them, yellow sarson, an oil-type B. rapa, has the characteristics of multiple ovaries. Its number of silique ventricles is four, and the seed number is significantly higher than that of Chinese cabbage. Zhao et al. [2] used AFLP markers to identify the developmental relationship of 161 materials from different $B$. rapa subspecies and demonstrated that yellow sarson is an independent group that has a relatively distant relationship with other subspecies. Other studies have shown that multilocular traits can increase the yield of seeds, and the width of the silique is positively correlated with thousand-seed weight [3]. Yadava et al. [4] found that the multilocular trait and wider silique width of yellow sarson may be due to the Bra034340 gene mutation in Chinese cabbage that is homologous to Arabidopsis CLAVATA3.

In the process of plant evolution, the self-incompatibility mechanism evolved [5]. Self-incompatibility is divided into sporophytic self-incompatibility (SSI) and gametophytic self-incompatibility (GSI) [6]. Brassica plants have sporophytic self-incompatibility, which is genetically controlled by an S-locus with multiple alleles called the S-haplotype $[7,8]$. There are three linked genes at the S-locus, namely S-locus glycoprotein $(S L G)$, S-locus receptor kinase (SRK) [9-11], and S-locus cysteine-rich protein $(S C R)$ or the S-locus protein 11 (SP11) [12,13]. The stigma localized SRK interact with SP11/SCR in the S-locus of Brassica plants to recognize self-pollen and cross-pollen. This interaction is based on the specificity of the S haplotype; that is, only SRK and SP11/SCR of the same haplotype can interact with each other, which causes self-incompatibility [14-16]. Owing to this feature, Chinese cabbage seed production requires breaking buds and selfing, which wastes a lot of manpower and increases the cost. Thus, the introduction of self-compatibility genes into Chinese cabbage would be of great significance for self-fertilization breeding and preservation of important germplasm resources.

Clubroot disease is an obligate parasitic soil-borne disease caused by Plasmodiophora brassicae Woron. It mainly harms cruciferous crops and is distributed in most countries and regions around the world [17]. It is estimated that 3 to 4 million hectares of farmland in China are threatened by this disease every year, causing $20-30 \%$ yield losses $[18,19]$. However, it is difficult to prevent and control the disease through physical and chemical methods $[20,21]$ because the resting spores of $P$. brassicae can survive in the soil for many years [22]. At present, breeding-resistant varieties are the most effective and economical prevention methods. To date, several CR loci have been identified by genetic mapping/quantitative trait locus (QTL) mapping in $B$. rapa using different resistance resources, including $\mathrm{Crr1}, \mathrm{Crr} 2, \mathrm{Crr} 3, \mathrm{Crr} 4, \mathrm{CR} a, \mathrm{CRb}, \mathrm{CRc}, \mathrm{CRd}, \mathrm{CRk}, \mathrm{PbBa3} .1, \mathrm{PbBa3} .2$. PbBa8.1, Rcr1, Rcr4, and Rcr9 [23-33]. These CR loci and their corresponding linkage markers enable the introgression of a single CR gene or pyramiding of multiple CR genes into one variety through marker-assisted selection (MAS).

The marker-assisted pyramiding strategy that introgresses multiple QTL/genes for one or multiple traits has been widely used in several crops such as soybean (multiple Rpp genes for Asian soybean rust resistance) [34] and rice (Bph27 (t) and Bph3 for brown planthopper resistance [35]; $R$ genes for blast-resistance [36]). In Brassica crops, Shah et al. [37] developed a new gene pyramided Brassica napus line by combining two clubroot resistant genes, $C R b$ and $P b B a 8.1$, which showed strong resistant to $P$. brassicae field isolates. Matsumoto et al. [38] accumulated three clubroot resistant genes $(C R a, C R k$, and $C R c$ ) through MAS in Chinese cabbage. Accumulation of multiple CR-QTL in B. oleracea conferred broad-spectrum clubroot resistance against six P. brassicae isolates [39]. The above reports were mostly based on the pyramiding of different genes for one trait. In common wheat, eight genes for seven different traits were introgressed into one cultivar. The improved pyramided lines exhibited resistance against three rusts and excellent quality [40]. However, at present, there are fewer reports on gene pyramiding in Chinese cabbage. In this study, we pyramided genes for multilocular, self-compatibility, and clubroot resistance into one material using MAS. The result provides new insights into the creation and breeding of new Chinese cabbage resources. 


\section{Materials and Methods}

\subsection{Plant Material}

Two B. rapa inbred lines, namely, 'CR BJN3-2' and 'KYS,' were used in this study. CR BJN3-2, a near-isogenic line of Chinese cabbage 'BJN3-2,' which is susceptible to clubroot disease and carries the resistance allele $C R b$ [28], was used as a recurrent parent [41]. It was a bilocular and self-incompatible material. The donor, parental line KYS (B. rapa L. var. yellow sarson), is an oil-type B. rapa with tetralocular ovaries, self-compatibility, yellow seed coat, and clubroot susceptibility.

\subsection{Marker Development, Validation, and Phenotype Genetic Analysis}

Yadava et al. [4] identified a major QTL tet-o for tetralocular ovary for B. rapa and predicted BrCLAVATA3 (Bra034340) as the candidate gene. Simple sequence repeats (SSRs) were searched based on the BrCLAVATA3 gene sequence using SSRHunter 1.3, and two SSR markers were designed for polymorphism screening between two parental lines (Table S1). The PCR reaction and amplification conditions for genotyping with SSR markers has been previously described by Li et al. [42] and Ge et al. [43].

For self-compatibility-related genes, we used multiplex PCR to screen co-dominant marker combinations based on multiple reported primers designed based on SRK, SLG, and SP11 genes and their genomic regions (Table S2). PCR amplification of genomic DNA using a $20 \mu \mathrm{L}$ reaction volume containing $3 \mu \mathrm{L}$ of genomic DNA, $1 \mu \mathrm{L}$ of each of the forward and reverse primer, $10 \mu \mathrm{L}$ of $10 \times$ PCR buffer, and $5 \mu \mathrm{L}$ of ddH2O to complete the reaction volume. PCR products were detected using $2 \%$ agarose gel electrophoresis. Additionally, four SSR and one InDel marker reported by Zhang et al. [44] were used for polymorphism screening of the $C R b$ gene. All polymorphic markers were then tested for linkage in the $\mathrm{F}_{2}$ population of CR BJN3-2 and KYS. Chi-square fitness was used to detect the separation of phenotype and genotype.

\subsection{Crossing Program and MAS for Gene Pyramiding}

To introduce the multilocular and self-compatibility genes carried by KYS into the clubroot disease-resistant line CR BJN3-2, we designed a set of backcross breeding programs. The two paternal lines were crossed to produce the $F_{1}$ hybrid, which was then backcrossed to produce $\mathrm{BC}_{4} \mathrm{~F}_{1}$, using CR BJN3-2 as the recurrent parent, accompanied by MAS in each generation. Subsequently, $\mathrm{BC}_{4} \mathrm{~F}_{2}$ was generated by selfing the selected $\mathrm{BC}_{4} \mathrm{~F}_{1}$ lines (Figure 1). Finally, the new pyramided line $\left(\mathrm{BC}_{4} \mathrm{~F}_{3}\right)$ with high genetic background recovery of the recurrent parent CR BJN3-2, high rate of tetralocular, self-compatibility, and clubroot resistance was obtained.

The screening method for the $\mathrm{BC}_{n} \mathrm{~F}_{\mathrm{n}}$ generation is detailed in Figure 1, which mainly included the foreground marker selection of the target genes, background marker selection of the genome, and phenotypic screening. The marker information used for target gene foreground selection is shown in Table 1. For genetic background selection, SSR markers developed previously $[45,46]$ and distributed on 10 chromosomes of the Chinese cabbage genome were used to determine polymorphisms. The polymorphic markers were used in subsequent genomic background screening.

In $\mathrm{BC}_{1} \mathrm{~F}_{1}$, low-density markers were used for background selection, and plants with higher recovery rates were selected for backcrossing. In the $\mathrm{BC}_{3} \mathrm{~F}_{1}$ generation, we increased the background selection marker density to have a clearer understanding of the genetic composition of the background and select individuals with a higher genomic background recovery rate. 


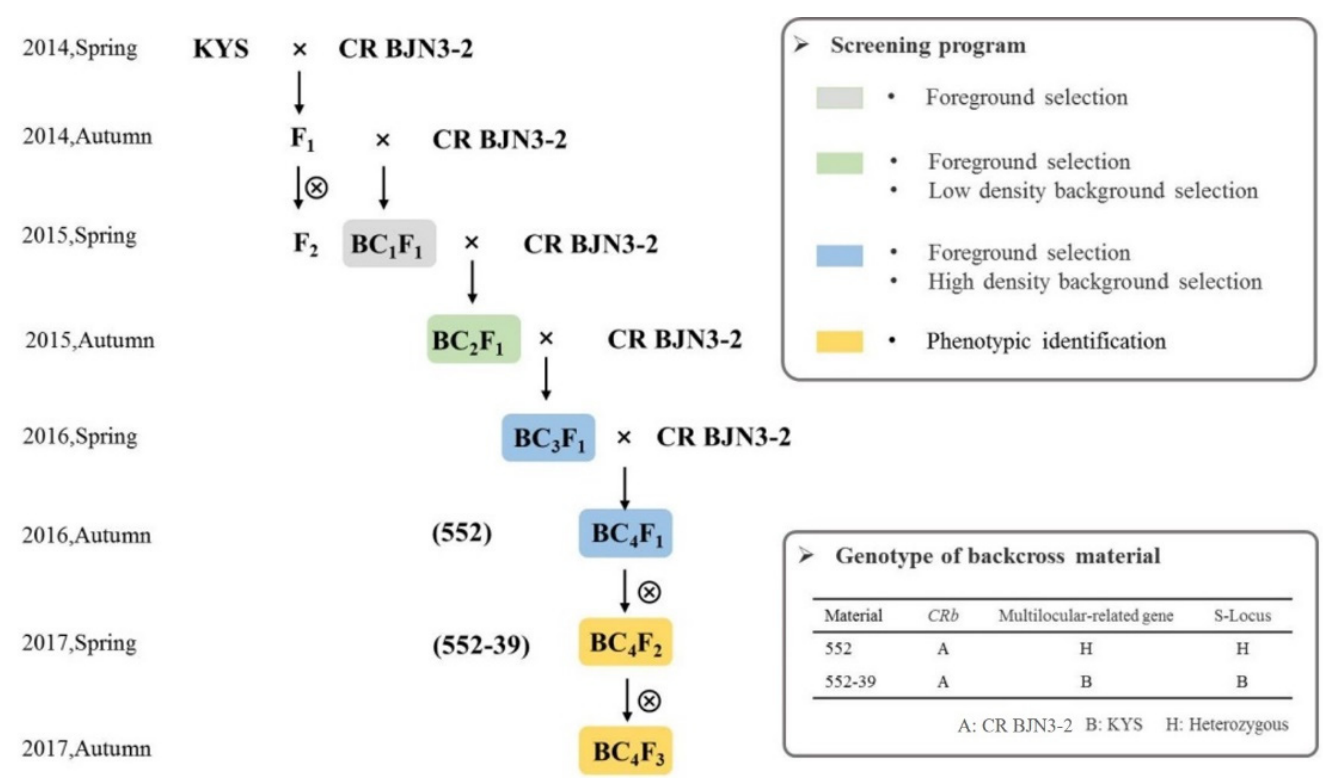

Figure 1. Schematic illustration of marker-assisted gene pyramiding in this study. CR BJN3-2: recurrent parent; KYS: donor parent; 552: selected $\mathrm{BC}_{4} \mathrm{~F}_{1}$ plant; 552-39: selected pyramided line. A: genotype of CR BJN3-2; B: genotype of KYS; H: heterozygous genotype.

Table 1. Molecular marker information for foreground selection of three targeted loci.

\begin{tabular}{ccccc}
\hline Gene & $\begin{array}{c}\text { Chromosomal } \\
\text { Location }\end{array}$ & Markers & Type of Marker & Character \\
\hline Bra034340 & A4 & sau_um190 & Based on PCR & Co-dominant \\
& & cun_146a & Based on PCR & Co-dominant \\
S-Locus & A7 & PK1+PK4/Sal-SLGI & Based on PCR & Co-dominant \\
& & SCF-6 & CSR & Co-dominant \\
& A3 & SC-12 & SCR & Co-dominant \\
& & TCR74 & SSR & Co-dominant \\
& & SSR & Co-dominant \\
\hline
\end{tabular}

\subsection{Phenotypic Characterization}

P. brassicae pathotype 4, defined by Williams' system [47] in a previous study [44], was used to test clubroot resistance in the parental and pyramided lines. The isolate was propagated in the susceptible Chinese cabbage lines as described by Piao et al. [28]. The swollen infected roots, which were soaked in water, were blended into solution and then filtrated with gauze. The filtrate was collected in a $50-\mathrm{mL}$ centrifuge tube, dissolved in sterile water, and finally stored in a refrigerator at $4{ }^{\circ} \mathrm{C}$. Resting spores were adjusted to the concentration of $10^{7}$ spores $/ \mathrm{mL}$ for inoculation by injecting the soil around thirty-day-old plants. The disease resistance of the plants was investigated at 45 days after infection. If the plant grew normally and there were no visible clubs in the main roots and fibrous roots, it was recorded as disease resistant and scored as level 0 . A few small swollen clubs on the lateral roots indicated level 1. If the lateral roots or main root had larger clubs, it was scored as level 2, and significant taproot swelling was classed as level 3.

The self-compatibility of plants was determined by the self-compatibility index (SCI), which was evaluated as the ratio of the total number of seeds to the number of pods in self-pollinated flowers. The self-incompatibility type was defined as SCI less than 1, and the self-compatibility type was defined as SCI greater than 1.

The agronomic traits of Chinese cabbage during the harvest period, including plant height, plant width, plant weight, number of outer leaves, leaf length, leaf width, petiole length, petiole width, petiole color, head weight, head shape, head solidity, head length, 
head width, head color, stem length, and stem width, as described by Ge et al. [43], were investigated in pyramided and recurrent parental lines. The $t$-test analysis was performed between pyramided line and recurrent parental line at $p \leq 0.05$ significant level.

\section{Results}

\subsection{Marker Development and Genetic Analysis for Multilocular and Self-Compatibility Traits}

Two SSR markers, Teo-1 and Teo-2, based on the candidate gene BrCLAVATA3 for multilocular, were designed (Table S1). Both markers showed polymorphism between CR BJN3-2 and KYS. Teo-1 with more motif repeats was selected as a linked marker for further analysis.

Among eight pairs of marker combinations designed for self-compatibility, as shown in Table S2, PCR bands were amplified only in KYS using PK1+PK4 and in CR BJN3-2 using Sal-SRKI and Sal-SLGI. PCR products were not detected using PS3+PS21, Sal-SLGII, Sal-SRKII, and SP11II between the two parents (Figure S1). To develop a codominant marker for self-compatibility, we conducted multiplex PCR by combining the PK1+PK4 primer with Sal-SRKI and Sal-SLGI. As shown in Figure 2, the PK1+PK4/Sal-SLGI primer combination could be used as a co-dominant marker to identify self-compatibility.

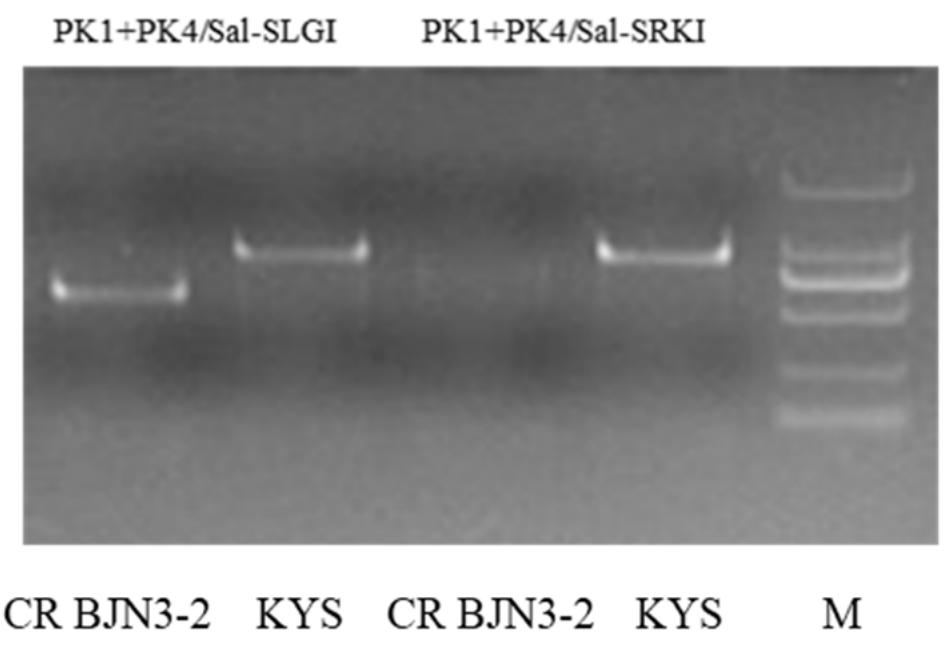

Figure 2. Multiplex PCR showing polymorphism of two pairs of primer combinations (PK1+PK4/SalSLGI; PK1+PK4/Sal-SRKI) between two parents (CR BJN3-2 and KYS). M: The DNA ladder 2000.

To perform genetic analysis and verify the molecular markers for locular and selfcompatibility phenotypes, the $\mathrm{F}_{1}$ population was generated by reciprocal crossing of $\mathrm{CR}$ BJN3-2 and KYS, and the $F_{2}$ population was constructed by selfing the $F_{1}$ generation. The $F_{1}$ generations showed bilocular and self-incompatibility, which indicated that the inheritance of multilocular and self-compatibility traits was not affected by a reciprocal cross. Both multilocular and self-incompatibility traits had no cytoplasmic effect and were genetically controlled by recessive nuclear genes.

Furthermore, a total of $204 \mathrm{~F}_{2}$ individual plant phenotypes were investigated. Ventricular traits were segregated among the $\mathrm{F}_{2}$ population. Of the individuals, 164 had bilocular ovaries and 40 had multilocular ovary (trilocular and tetralocular). The separation ratio of bilocular to multilocular was 3:1 according to the chi-square test $\left(\chi^{2}=2.8824\right)$, indicating that the ventricular traits are genetic traits controlled by a pair of genes. Moreover, the genotype of the $\mathrm{F}_{2}$ population using the Teo- 1 marker was consistent with the ventricular phenotype (Figure 3), which could be used as a linkage marker for further MAS. 

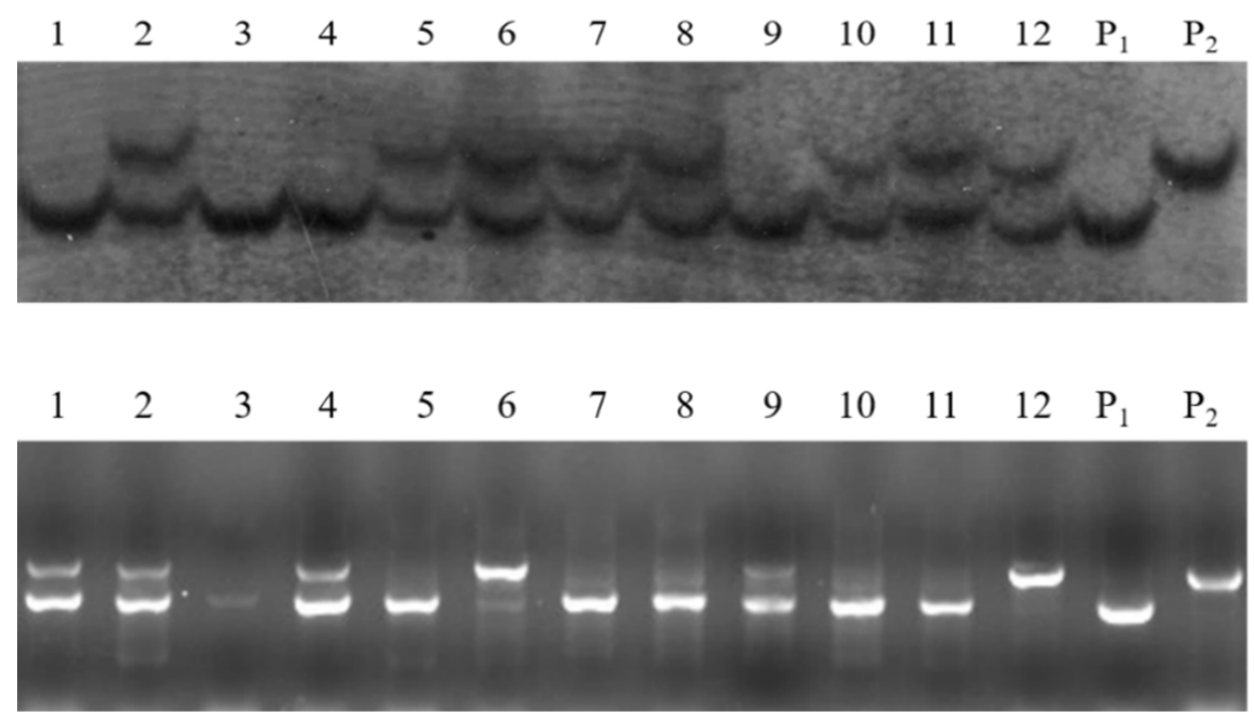

Figure 3. Genotype of partial individuals of $\mathrm{F}_{2}$ population for locular number (up) and selfcompatibility (down). $\mathrm{P}_{1}$ : CR BJN3-2; $\mathrm{P}_{2}$ : KYS; 1-12: $\mathrm{F}_{2}$ individual plant number.

In addition, among $204 \mathrm{~F}_{2}$ plants, 149 individual plants showed self-incompatibility and 55 individuals showed self-compatibility. The ratio of self-compatible to self-incompatible plants was close to $1: 3$ by the chi-square fitness test $\left(\chi^{2}=0.3203\right)$, indicating that selfcompatibility is controlled by a pair of genes. The genotype of $204 \mathrm{~F}_{2}$ plants detected by the newly developed marker PK1+PK4/Sal-SLGI was also identical to this phenotype (Figure 3).

\subsection{Polymorphic Marker Screening for Foreground Selection}

For clubroot resistance, five $C R b$ gene linked markers developed by Zhang et al. [44] were used for polymorphism detection, as shown in Table S1. TCR74 and TCR79, which were closely linked with $C R b$, showed polymorphism between two parental lines, which were selected as foreground markers. For self-compatibility, 12 SSR markers were developed in the chromosome region of SI-related genes SRK, SLG, and SP11 (Table S1). Among them, SCF- 6 and SC-12 showed polymorphism between CR BJN3-2 and KYS. Thus, SCF-6, SC-12, and gene-based PK1+PK4/Sal-SLGI (Figure 2) were used as foreground selection markers, co-segregating with self-compatibility. Two flanking SSR markers of BrCLAVATA3, sau_um190, and cun_146a, showing polymorphism between CR BJN3-2, KYS, and Teo-1, were used as selection markers for the multilocular trait.

All markers used in this study were co-dominant markers that could clearly distinguish heterozygous and homozygous plants. Detailed information for these markers is shown in Table 1.

\subsection{Polymorphic Markers Screening for Background Selection of the Whole Genome}

Among 1140 genomic SSR markers [45,46], 319 pairs showed polymorphism between two parents, and the polymorphism ratio was $28.0 \%$. For background selection of each generation, 111 pairs of markers were chosen. The numbers of these 111 background selection markers distributed on $10 \mathrm{~B}$. rapa chromosomes were 10, 9, 11, 12, 11, 11, 12, 10, 13 , and 12 , respectively. The average interval of these markers was $2.25 \mathrm{Mb}$, and the total physical distance covered was $249.27 \mathrm{Mb}$ (Table S3). The distribution of these markers on the 10 chromosomes is shown in Figure 4. 


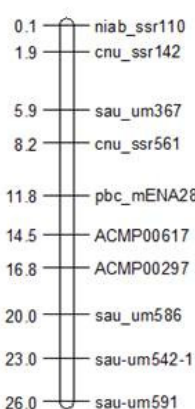

A6

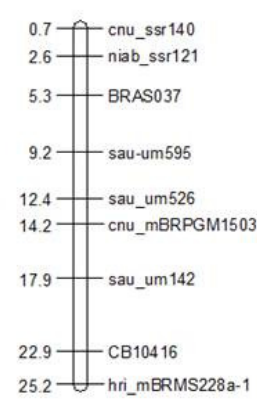

A7
A3

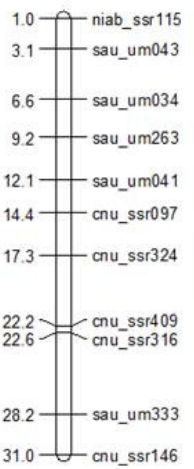

A8
A4

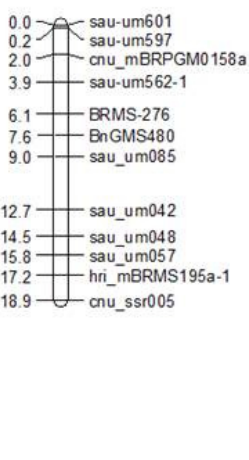

A9

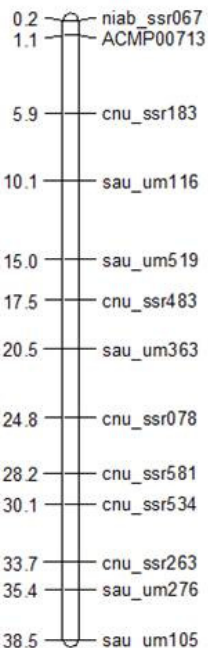

A5

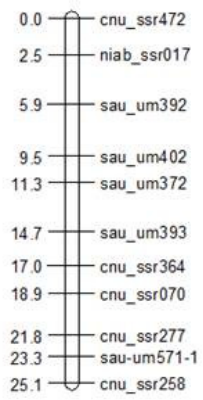

A10

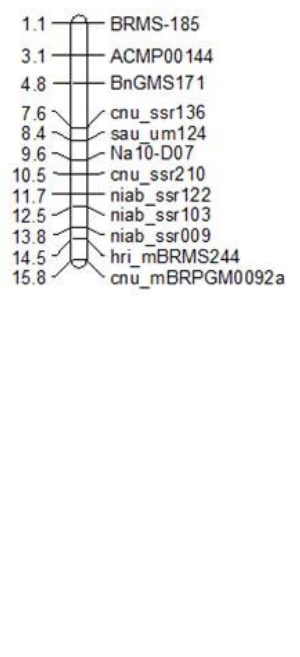

Figure 4. Distribution of 111 background selection markers on 10 B. rapa chromosomes (A1-A10).

\subsection{Marker-Assisted Pyramiding of Multilocular, Self-Compatibility, and CRb Genes}

Using the co-segregation markers for multilocular, self-compatibility, and $C R b$ genes, foreground selection was exercised in each generation of backcross hybrids from $\mathrm{BC}_{1} \mathrm{~F}_{1}$ to $\mathrm{BC}_{4} \mathrm{~F}_{1}$ (Figure 1). Among $100 \mathrm{BC}_{1} \mathrm{~F}_{1}, 9$ plants that carried all 3 loci in heterozygous condition were selected to perform background genomic screening in low marker density (37 SSR markers). Four plants with an average of $51 \%$ genomic recovery were used to raise $\mathrm{BC}_{2} \mathrm{~F}_{1}$. Ten plants among $276 \mathrm{BC}_{2} \mathrm{~F}_{1}$, which were "positive" in three loci, were used for background selection using 21 markers that were not recovered in recurrent parental genotypes. Four plants with an average genomic recovery of $74.12 \%$ were backcrossed to generate the $\mathrm{BC}_{3} \mathrm{~F}_{1}$ progeny. In the $\mathrm{BC}_{3} \mathrm{~F}_{1}$ generation, 10 of the 300 plants were found to be heterozygous for three targeted loci. A high marker density background assay revealed that the genomic recovery of these 10 plants ranged from 78.10 to $86.67 \%$, and these plants were backcrossed to produce $\mathrm{BC}_{4} \mathrm{~F}_{1}$. In $\mathrm{BC}_{4} \mathrm{~F}_{1}$, we found that 10 of 154 plants were triple heterozygous, and their background recovery ranged from 88.18 to $94.55 \%$ (Figure 5). Four well-growing plants with high recovery were then self-pollinated to generate the $\mathrm{BC}_{4} \mathrm{~F}_{2}$ population. Ten homozygous $\mathrm{BC}_{4} \mathrm{~F}_{2}$ plants for three target loci were propagated for $\mathrm{BC}_{4} \mathrm{~F}_{3}$. One best line with $95 \%$ recovery, namely, '552-39,' was finally selected for the phenotypic assay. 


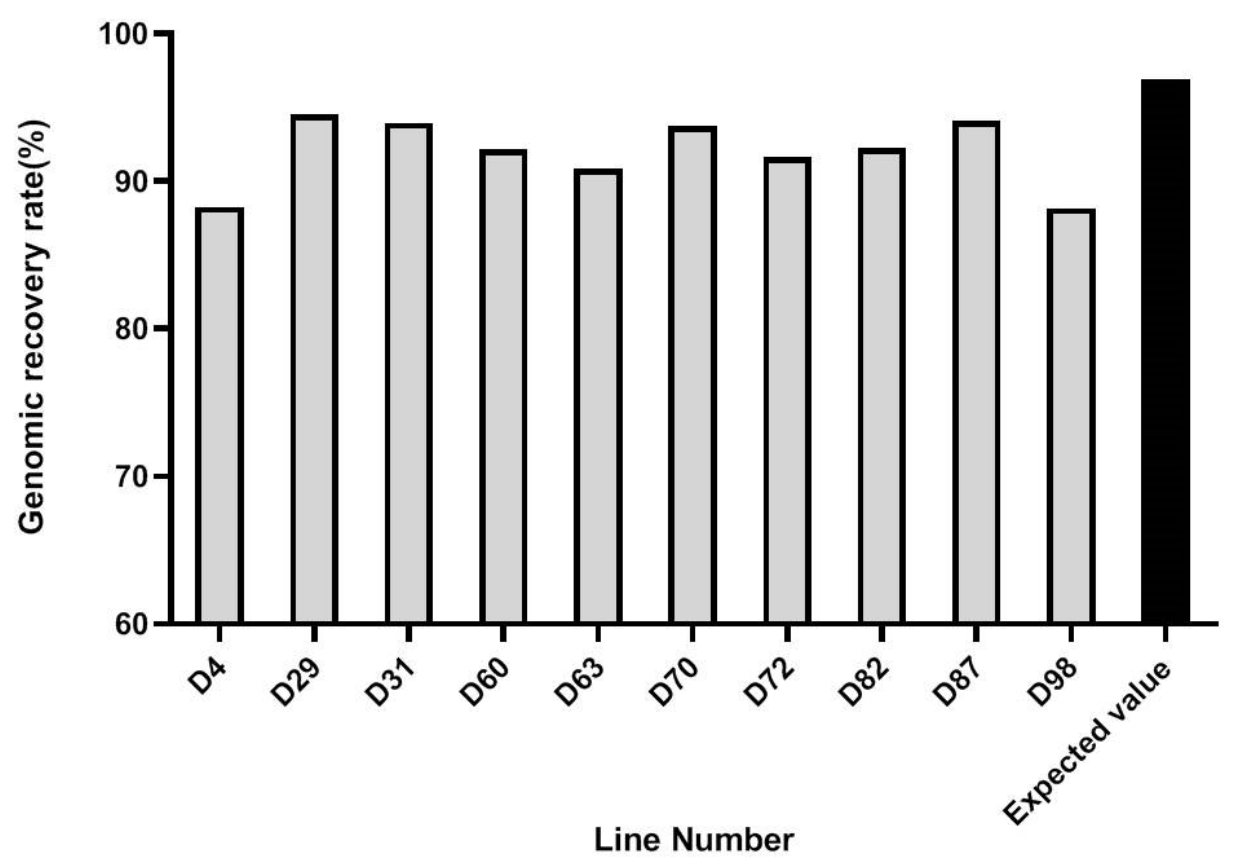

Figure 5. Genomic background recovery rate of ten $\mathrm{BC}_{4} \mathrm{~F}_{1}$ individual plants (D4-D98). Black bar chart represented the expected value of genomic recovery rate of $\mathrm{BC}_{4} \mathrm{~F}_{1}$ generation.

\subsection{Phenotypic Evaluation of a Pyramided Line}

The clubroot-resistant parent CR BJN3-2, possessing the $C R b$ gene, exhibited high resistance to $P$. brassicae pathotype 4 , and the negative control, BJN3-2, was susceptible. The pyramided line 552-39 showed high resistance with a low disease incidence rate and disease index value (Figure 6, Table 2).

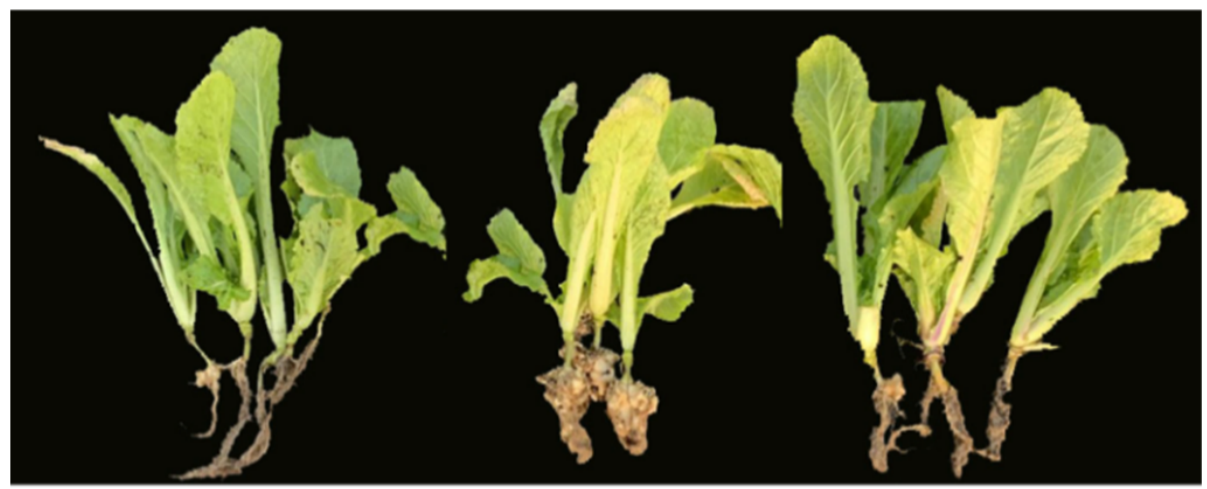

CR BJN3-2

BJN3-2

$552-39$

Figure 6. Phenotypic investigation of clubroot resistance for the pyramided line and two parental lines. CR BJN3-2: recurrent parent; BJN3-2: susceptible line as control; 552-39: selected pyramided line.

Table 2. Phenotypic investigation of clubroot resistance.

\begin{tabular}{ccccccc}
\hline Material & Level 0 & Level 1 & Level 2 & Level 3 & $\begin{array}{c}\text { Disease } \\
\text { INCIDENCE (\%) }\end{array}$ & $\begin{array}{c}\text { Disease } \\
\text { Index (DI) }\end{array}$ \\
\hline CR BJN3-2 & 30 & 3 & 6 & 5 & 31.8 & 23.5 \\
BJN3-2 & & & & 50 & 100 & 100 \\
$552-39$ & 48 & & & 2 & 4 & 4 \\
\hline
\end{tabular}

Note: The table shows the number of plants at different levels of clubroot disease. 
Ten homozygous pyramided plants were evaluated for multi-ventricular and selfcompatibility traits after two weeks of selfing. The 10 individuals were all multilocular, as shown in Figure 7. The SCI for these 10 plants was greater than 1, which was expressed as self-compatibility (Table 3).

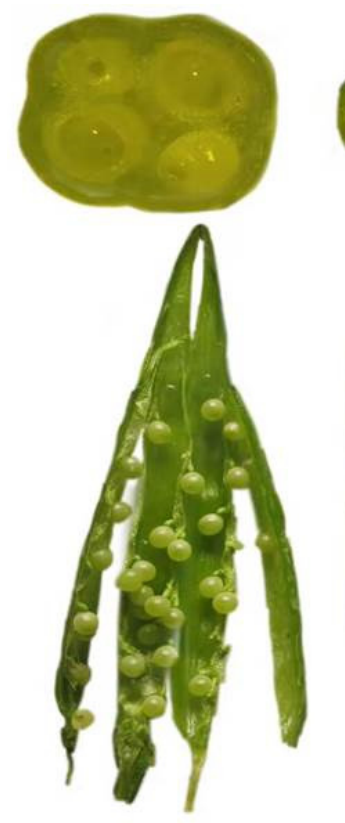

552-39
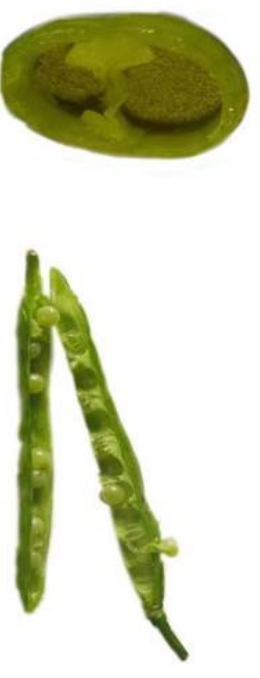

CR BJN3-2

Figure 7. Phenotypic investigation of locule number for the pyramided line and two parental lines. CR BJN3-2: recurrent parent; 552-39: selected pyramided line.

Table 3. Self-compatibility index (SCI) of the pyramided line 552-39 and two parental lines (CR BJN3-2 and KYS).

\begin{tabular}{cc}
\hline Material & SCI \\
\hline CR BJN3-2 & $0.48 \pm 0.02$ \\
KYS & $1.37 \pm 0.29$ \\
$552-39$ & $1.15 \pm 0.18$ \\
\hline
\end{tabular}

Moreover, 50 improved pyramided plants of the 552-39 line were grown in the open field together with recurrent parent CR BJN3-2. Agronomy-related traits were investigated in their heading stage. The results showed that the pyramided line was not significantly different from the recurrent parent in terms of heading-related and yield traits (Table 4).

Table 4. Agronomic trait evaluation of recurrent parent and pyramided line.

\begin{tabular}{ccc}
\hline Agronomic Traits & $\mathbf{5 5 2 - 3 9}$ & CR BJN3-2 \\
\hline Plant height $(\mathrm{cm})$ & $35.3 \pm 0.58$ & $34.5 \pm 4.95$ \\
Plant width $(\mathrm{cm})$ & $49.0 \pm 7.00$ & $48.0 \pm 0.00$ \\
Plant weight $(\mathrm{kg})$ & $2.23 \pm 0.29$ & $2.17 \pm 0.15$ \\
Number of outer leaves & $25.7 \pm 3.06$ & $19.5 \pm 2.12$ \\
Leaf length $(\mathrm{cm})$ & $32.0 \pm 1.73$ & $34.0 \pm 2.12$ \\
Leaf width $(\mathrm{cm})$ & $19.8 \pm 2.75$ & $21.0 \pm 0.00$ \\
\hline
\end{tabular}


Table 4. Cont.

\begin{tabular}{ccc}
\hline Agronomic Traits & $\mathbf{5 5 2 - 3 9}$ & CR BJN3-2 \\
\hline Petiole length $(\mathrm{cm})$ & $18.5 \pm 1.00$ & $17.8 \pm 1.06$ \\
Petiole width $(\mathrm{cm})$ & $5.3 \pm 0.58$ & $5.5 \pm 0.71$ \\
Petiole color & Green & Green \\
Head weight $(\mathrm{kg})$ & $1.16 \pm 0.17$ & $1.09 \pm 0.08$ \\
Head shape & Folded & Folded \\
Head solidity & Compaction & Compaction \\
Head length $(\mathrm{cm})$ & $27.7 \pm 2.84$ & $23.9 \pm 0.21$ \\
Head width $(\mathrm{cm})$ & $12.8 \pm 2.47$ & $10.7 \pm 0.35$ \\
Head color & Pale Yellow & Pale Yellow \\
Stem length $(\mathrm{cm})$ & $2.83 \pm 1.26$ & $3.25 \pm 0.35$ \\
Stem width $(\mathrm{cm})$ & $2.30 \pm 0.75$ & $2.90 \pm 0.14$
\end{tabular}

Significance level at $p \leq 0.05$.

\section{Discussion}

The large number of gene/QTL mapping studies for diverse crops has provided an abundance of molecular markers associated with traits [48]. The use of MAS combined with the backcross strategy allows the introgression of multiple target genes into one elite cultivar or line, which enhances the precision and efficiency of the breeding program.

Self-compatibility in $B$. rapa crops is a characteristic with a complex genetic mechanism [49]. To improve this trait, conventional breeding is difficult and time-consuming. In our study, a co-dominant marker combination Sal-SLGI/PK1+PK4 based on well-known self-compatibility genes was developed and verified in the $\mathrm{F}_{2}$ population. It also showed a better foreground selection efficiency in the pyramiding process.

Genetic analysis using segregation populations of CR BJN3-2 and KYS demonstrated that the bilocular silique phenotype was dominant over the tetralocular phenotype, which was coincident with previous studies $[3,4]$. We found that both trilocular and tetralocular types appeared on a single plant in $\mathrm{F}_{2}$ individuals and backcross progeny, even though their genotypes were the same as KYS detected by linkage marker Teo-1. Xu et al. [50] reported that two independent recessive genes controlled the trait of a trilocular silique. We predicted that other loci/genes probably control a trilocular silique or interact with the major QTL tet-o for a multilocular silique in B. rapa. Therefore, we finally selected 552-39, which had the highest tetralocular ratio, as the best pyramided line.

The recurrent parent CR BJN3-2, harboring the CRb gene, is resistant to P. brassica pathotype $4[29,44]$. Phenotypic investigation showed that the pyramided line had strong clubroot resistance, indicating the successful MAS strategy. Owing to the isolate-specific association between CR genes and P. brassicae, multiple CR gene pyramiding challenged us for resistant breeding. Shah et al. [37] combined $C R b$ and $P b B a 8.1$ genes and developed a pyramided homozygous inbred line of $B$. napus that was resistant to various $P$. brassicae isolates. In rice, many studies have focused on developing disease-resistant lines that introgress multiple resistance genes [51,52]. Several studies found that pyramiding three or more bacterial blight $(\mathrm{BB})$ resistance genes exhibited higher resistance than the lines with one or two genes $[53,54]$. The developed pyramided line, 553-39, could be used as a recurrent parent for further gene pyramiding of other CR genes. Multiple CR gene pyramiding would facilitate not only the creation of resistance resources but also CR gene interaction studies in the future.

The percentages of recurrent parent genomes referring to \%RPG in the backcross population reflect the degree of recovery of the genetic material of a single plant to the recurrent parent [55]. Many studies have shown that increasing the genomic distance between background markers could improve the efficiency of foreground selection, thereby reducing the population size required, but the reduction of marker density increased the length of donor fragments, which was prone to linkage drag. Therefore, it is not possible to rely solely on molecular markers for selection; foreground marker selection combined with phenotype identification was necessary to achieve the desired goal. 
In our study, the background selection marker of the previous generation, which was restored to the recurrent parent genotype, was not used in the next generation. Before the $\mathrm{BC}_{2} \mathrm{~F}_{1}$ generation, the average genetic background recovery rate of each generation was significantly lower than the expected value of the genetic background recovery rate. Although the $\mathrm{BC}_{4} \mathrm{~F}_{1}$ generation recovered, it still did not meet the expected value. This result was also found in previous gene pyramiding studies in other crops $[54,56]$. The reduction in the recovery rate of the recurrent parent's genomic background was influenced by the backcross population size, linkage drag, number of background selection markers, and purity of the recurrent parents $[40,48]$.

In conclusion, we introgressed multilocular and self-compatibility trait in the background of CR BJN3-2, which carries the $C R b$ gene to improve seed yield and clubroot resistance. The improved pyramided line recovered the agro-morphological phenotype of recurrent parents and could be released as a potential resource for Chinese cabbage breeding.

Supplementary Materials: The following supporting information can be downloaded at: https: / / www.mdpi.com/article/10.3390/horticulturae8020139/s1, Figure S1: Screening results of polymorphic markers; Table S1: Molecular markers designed for foreground selection of three targeted loci; Table S2: Self-compatibility primers designed based on the sequences of the SLG, SRK, and SP11 genes; Table S3: Background selection marker distribution on ten chromosomes of Brassica rapa.

Author Contributions: J.Z. performed experiments and data analysis as well as manuscript drafting. H.Z. and Y.M. performed the marker development and backcross strategies. M.J. and Z.Z. helped with phenotype investigation and manuscript drafting. X.L. and Z.P. conceived the project and designed the research. All authors have read and agreed to the published version of the manuscript.

Funding: This work was supported by LiaoNing Revitalization Talents Program (XLYC2002034) and China Agriculture Research System of MOF and MARA (CARS-12). This work was also supported by the National Natural Science Foundation of China (No. 31772326).

Institutional Review Board Statement: Not applicable.

Informed Consent Statement: Not applicable.

Data Availability Statement: The study did not report any data.

Acknowledgments: We thank LetPub (www.letpub.com) for its linguistic assistance during the preparation of this manuscript.

Conflicts of Interest: The authors declare that they have no conflict of interest.

\section{References}

1. Nagaharu, U. Genome analysis in Brassica carinata with special reference to the experimental formation of Brassica napus, a peculiar mode of fertilization. Jpn. J. Bot. 1935, 7, 389-452.

2. Zhao, J.; Wang, X.; Deng, B.; Lou, P.; Bonnema, G. Genetic relationships within Brassica rapa as inferred from AFLP fingerprints. Theor. Appl. Genet. 2005, 110, 1301-1314. [CrossRef] [PubMed]

3. Somnath, R.; Sinhamahapatra, S.P. Relationship between seed yield and yield components in bilocular and tetralocular yellow sarson (Brassica rapa). Indian J. Agric. Sci. 2011, 81, 643-647.

4. Yadava, S.K.; Paritosh, K.; Panjabi-Massand, P.; Gupta, V.; Chandra, A.; Sodhi, Y.S.; Pradhan, A.K.; Pental, D. Tetralocular ovary and high silique width in yellow sarson lines of Brassica rapa (subspecies trilocularis) are due to a mutation in Bra034340 gene, a homologue of CLAVATA3 in Arabidopsis. Theor. Appl. Genet. 2014, 127, 2359-2369. [CrossRef]

5. Takayama, S.; Isogai, A. Self-incompatibility in plants. Annu. Rev. Plant Biol. 2005, 56, 467-489. [CrossRef]

6. Yamamoto, M.; Nishio, T. Commonalities and differences between Brassica and Arabidopsis self-incompatibility. Hortic. Res. 2014, 1, 14054. [CrossRef]

7. Bateman, A.J. Self-incompatibility systems in angiosperms: III. Crucif. Hered. 1955, 9, 53-68. [CrossRef]

8. Nasrallah, J.B.; Nishio, T.; Nasrallah, M.E. The Self-incompatibility genes of Brassica: Expression and use in genetic ablation of floral tissues. Plant Mol. Biol. 1991, 42, 393-422. [CrossRef]

9. Watanabe, M.; Takasaki, T.; Toriyama, K.; Yamakawa, S.; Isogai, A.; Suzuki, A.; Hinata, K. A high degree of homology exists between the protein encoded by SLG and the S receptor domain encoded by SRK in self-incompatible Brassica campestris L. Plant Cell Physiol. 1994, 35, 1221-1229. [CrossRef]

10. Stein, J.C.; Howlett, B.; Boyes, D.C.; Nasrallah, M.E.; Nasrallah, J.B. Molecular cloning of a putative receptor protein kinase gene encoded at the self-incompatibility locus of Brassica oleracea. Proc. Natl. Acad. Sci. USA 1991, 88, 8816-8820. [CrossRef] 
11. Hatakeyama, K.; Takasaki, T.; Watanabe, M.; Hinata, K. Molecular characterization of S locus genes, SLG and SRK, in a pollenrecessive self-incompatibility haplotype of Brassica rapa L. Genetics 1998, 149, 1587-1597. [CrossRef]

12. Schopfer, C.R.; Nasrallah, M.E.; Nasrallah, J.B. The male determinant of self-incompatibility in Brassica. Science 1999, 286, 1697-1700. [CrossRef]

13. Suzuki, G.; Kai, N.; Hirose, T.; Fukui, K.; Nishio, T.; Takayama, S.; Isogai, A.; Watanabe, M.; Hinata, K. Genomic organization of the $S$ locus: Identification and characterization of genes in SLG/SRK region of S(9) haplotype of Brassica campestris (syn. rapa). Genetics 1999, 153, 391-400. [CrossRef]

14. Kachroo, A.; Schopfer, C.R.; Nasrallah, M.E.; Nasrallah, J.B. Allele-specific receptor-ligand interactions in Brassica selfincompatibility. Science 2001, 293, 1824-1826. [CrossRef] [PubMed]

15. Takayama, S.; Shimosato, H.; Shiba, H.; Funato, M.; Che, F.S.; Watanabe, M.; Iwano, M.; Isogai, A. Direct ligand-receptor complex interaction controls Brassica self-incompatibility. Nature 2001, 413, 534-538. [CrossRef]

16. Hiroko, S.; Yokota, N.; Shiba, H.; Iwano, M.; Entani, T.; Che, F.S.; Watanabe, M.; Isogai, A.; Takayama, S. Characterization of the SP11/SCR high-affinity binding site involved in self/nonself recognition in Brassica self-incompatibility. Plant Cell 2007, 19, 107-117.

17. Dixon, G.R. The occurrence and economic impact of plasmodiophora brassicae and clubroot disease. J. Plant Growth Regul. 2009, 28, 194-202. [CrossRef]

18. Jing, W.; Yun, H.; Li, X.; Li, H. Research progress in clubroot of crucifers. Plant Prot. 2011, 37, $153-158$.

19. Chai, A.L.; Xie, X.W.; Shi, Y.X.; Li, B.J. Special Issue: Research status of clubroot (Plasmodiophora brassicae) on cruciferous crops in China. Can. J. Plant Pathol. 2014, 36, 142-153. [CrossRef]

20. Donald, C.; Porter, I. Integrated Control of Clubroot. J. Plant Growth Regul. 2009, 28, 289-303. [CrossRef]

21. Kageyama, K.; Asano, T. Life Cycle of Plasmodiophora brassicae. J. Plant Growth Regul. 2009, 28, 203-211. [CrossRef]

22. Mehraj, H.; Akter, A.; Miyaji, N.; Miyazaki, J.; Shea, D.J.; Fujimoto, R.; Doullah, M.A.-U. Genetics of clubroot and fusarium wilt disease resistance in Brassica vegetables: The Application of marker assisted breeding for disease resistance. Plants 2020, 9, 726. [CrossRef] [PubMed]

23. Matsumoto, E.; Yasui, C.; Ohi, M.; Tsukada, M. Linkage analysis of RFLP markers for clubroot resistance and pigmentation in Chinese cabbage. Euphytica 1998, 104, 79-86. [CrossRef]

24. Suwabe, K.; Tsukazaki, H.; Iketani, H.; Hatakeyama, K.; Fujimura, M.; Nunome, T.; Fukuoka, H.; Matsumoto, S.; Hirai, M. Identification of two loci for resistance to clubroot (Plasmodiophora brassicae Woronin) in Brassica rapa L. Theor. Appl. Genet. 2003, 107, 997-1002. [CrossRef]

25. Suwabe, K.; Tsukazaki, H.; Iketani, H.; Hatakeyama, K.; Kondo, M.; Fujimura, M.; Nunome, T.; Fukuoka, H.; Hirai, M.; Matsumoto, S. Simple sequence repeat-based comparative genomics between Brassica rapa and Arabidopsis thaliana: The genetic origin of clubroot resistance. Genetics 2006, 173, 309-319. [CrossRef]

26. Hirai, M.; Harada, T.; Kubo, N.; Tsukada, M.; Suwabe, K.; Matsumoto, S. A novel locus for clubroot resistance in Brassica rapa and its linkage markers. Theor. Appl. Genet. 2004, 108, 639-643. [CrossRef]

27. Saito, M.; Kubo, N.; Matsumoto, S.; Suwabe, K.; Tsukada, M.; Hirai, M. Fine mapping of the clubroot resistance gene, Crr3, in Brassica rapa. Theor. Appl. Genet. 2006, 114, 81-91. [CrossRef]

28. Piao, Z.Y.; Deng, Y.Q.; Choi, S.R.; Park, Y.J.; Lim, Y.P. SCAR and CAPS mapping of CRb, a gene conferring resistance to Plasmodiophora brassicae in Chinese cabbage (Brassica rapa ssp. pekinensis). Theor. Appl. Genet. 2004, 108, 1458-1465. [CrossRef]

29. Chen, J.; Jing, J.; Zhan, Z.; Zhang, T.; Zhang, C.; Piao, Z. Identification of novel QTLs for isolate-specific partial resistance to plasmodiophora brassicae in Brassica rapa. PLoS ONE 2013, 8, e85307. [CrossRef]

30. Pang, W.; Fu, P.; Li, X.; Zhan, Z.; Yu, S.; Piao, Z. Identification and mapping of the clubroot resistance gene CRd in Chinese cabbage (Brassica rapa ssp. pekinensis). Front. Plant Sci. 2018, 9, 653. [CrossRef]

31. Yu, F.; Zhang, X.; Huang, Z.; Chu, M.; Song, T.; Falk, K.C.; Deora, A.; Chen, Q.; Yan, Z.; Mcgregor, L. Identification of genome-wide variants and discovery of variants associated with Brassica rapa clubroot resistance gene Rcr1 through bulked segregant RNA sequencing. PLoS ONE 2016, 11, e0153218. [CrossRef] [PubMed]

32. Yu, F.; Zhang, X.; Peng, G.; Falk, K.C.; Strelkov, S.E.; Gossen, B.D. Genotyping-by-sequencing reveals three QTL for clubroot resistance to six pathotypes of Plasmodiophora brassicae in Brassica rapa. Sci. Rep. 2017, 7, 4516. [CrossRef] [PubMed]

33. Zhen, H.; Peng, G.; Liu, X.; Abhinandan, D.; Falk, K.C.; Gossen, B.D.; Mcdonald, M.R.; Yu, F. Fine mapping of a clubroot resistance gene in Chinese Cabbage using SNP markers identified from bulked segregant RNA sequencing. Front. Plant Sci. 2017, 8, 1448.

34. Yamanaka, N.; Hossain Md, M. Pyramiding three rust-resistance genes confers a high level of resistance in soybean (Glycine max). Plant Breed. 2019, 138, 686-695. [CrossRef]

35. Liu, Y.; Chen, L.; Liu, Y.; Dai, H.; He, J.; Kang, H.; Pan, G.; Huang, J.; Qiu, Z.; Wang, Q.; et al. Marker assisted pyramiding of two brown planthopper resistance genes, Bph3 and Bph27 (t), into elite rice cultivars. Rice 2016, 9, 27. [CrossRef]

36. Xiao, W.; Yang, Q.; Huang, M.; Guo, T.; Liu, Y.; Wang, J.; Yang, G.; Zhou, J.; Yang, J.; Zhu, X.; et al. Improvement of rice blast resistance by developing monogenic lines, two-gene pyramids and three-gene pyramid through MAS. Rice 2019, 12, 78. [CrossRef]

37. Shah, N.; Li, Q.; Xu, Q.; Liu, J.; Huang, F.; Zhan, Z.; Qin, P.; Zhou, X.; Yu, W.; Zhu, L.; et al. CRb and PbBa8.1 synergically increases resistant genes expression upon infection of Plamodiophora brassicae in Brassica napus. Genes 2020, 11, 202. [CrossRef] [PubMed]

38. Matsumoto, E.; Ueno, H.; Aruga, D.; Sakamoto, K.; Hayashida, N. Accumulation of three clubroot resistance genes through marker-assisted selection in Chinese cabbage (Brassica rapa ssp. pekinensis). J. Jpn. Soc. Hortic. Sci. 2012, 81, 184-190. [CrossRef] 
39. Tomita, H.; Shimizu, M.; Doullah, M.A.U.; Fujimoto, R.; Okazaki, K. Accumulation of quantitative trait loci conferring broadspectrum clubroot resistance in Brassica oleracea. Mol. Breed. 2013, 32, 889-900. [CrossRef]

40. Tyagi, S.; Mir, R.R.; Kaur, H.; Chhuneja, P.; Ramesh, B.; Balyan, H.S.; Gupta, P.K. Marker-assisted pyramiding of eight QTLs/genes for seven different traits in common wheat (Triticum aestivum L.). Mol. Breed. 2014, 34, 167-175. [CrossRef]

41. Chen, J.; Pang, W.; Chen, B.; Zhang, C.; Piao, Z. Transcriptome analysis of Brassica rapa near-isogenic lines carrying clubrootresistant and -susceptible alleles in response to Plasmodiophora brassicae during early infection. Front. Plant Sci. 2016, 6, 1183. [CrossRef] [PubMed]

42. Li, X.; Ramchiary, N.; Choi, S.R.; VanNguyen, D.; Hossain, M.J.; Yang, H.; Lim, Y.P. Development of a high density integrated reference genetic linkage map for the multinational Brassica rapa Genome Sequencing Project. Genome 2010, 53, 939-947. [CrossRef] [PubMed]

43. Ge, Y.; Ramchiary, N.; Wang, T.; Liang, C.; Wang, N.; Wang, Z.; Choi, S.R.; Lim, Y.P.; Piao, Z.Y. Mapping quantitative trait loci for leaf and heading-related traits in Chinese cabbage (Brassica rapa L.ssp. pekinensis). Hortic. Environ. Biotechnol. 2011, 52, $494-501$. [CrossRef]

44. Zhang, T.; Zhao, Z.; Zhang, C.; Pang, W.; Choi, S.R.; Lim, Y.P.; Piao, Z. Fine genetic and physical mapping of the CRb gene conferring resistance to clubroot disease in Brassica rapa. Mol. Breed. 2014, 34, 1173-1183. [CrossRef]

45. Li, X.; Ramchiary, N.; Dhandapani, V.; Choi, S.R.; Hur, Y.; Nou, I.-S.; Yoon, M.K.; Lim, Y.P. Quantitative trait loci mapping in Brassica rapa revealed the structural and functional conservation of genetic loci governing morphological and yield component traits in the A, B, and C subgenomes of Brassica species. DNA Res. 2013, 20,1-16. [CrossRef]

46. Ge, Y.; Ramchiary, N.; Wang, T.; Liang, C.; Wang, N.; Wang, Z.; Choi, S.R.; Lim, Y.P.; Piao, Z.Y. Development and linkage mapping of unigene-derived microsatellite markers in Brassica rapa L. Breed. Sci. 2011, 61, 160-167. [CrossRef]

47. Williams, P.H. A system for the determination of races of Plasmodiophora brassicae that infect Cabbage and Rutabaga. Phytopathology $1966,56,624-626$.

48. Collard, B.C.Y.; Mackill, D.J. Marker-assisted selection: An approach for precision plant breeding in the twenty-first century. Philos. Trans. R. Soc. B Biol. Sci. 2008, 363, 557-572. [CrossRef]

49. Nasrallah, J.B. Plant mating systems: Self-incompatibility and evolutionary transitions to self-fertility in the mustard family. Curr. Opin. Genet. Dev. 2017, 47, 54-60. [CrossRef]

50. Xu, P.; Lv, Z.; Zhang, X.; Wang, X.; Pu, Y.; Wang, H.; Yi, B.; Wen, J.; Ma, C.; Tu, J.; et al. Identification of molecular markers linked to trilocular gene (mc1) in Brassica juncea L. Mol. Breed. 2014, 33, 425-434. [CrossRef]

51. Singh, A.K.; Singh, V.K.; Singh, S.P.; Pandian, R.T.P.; Ellur, R.K.; Singh, D. Molecular breeding for the development of multiple disease resistance in Basmati rice. AoB Plants 2012, 2012, pls029. [CrossRef]

52. Das, G.; Rao, G.J.N. Molecular marker assisted gene stacking for biotic and abiotic stress resistance genes in an elite rice cultivar. Front. Plant Sci. 2015, 6, 698. [CrossRef] [PubMed]

53. Ramalingam, J.; Raveendra, C.; Savitha, P.; Vidya, V.; Chaithra, T.L.; Velprabakaran, S.; Saraswathi, R.; Ramanathan, A.; Pillai, M.P.A.; Arumugachamy, S.; et al. Gene Pyramiding for achieving enhanced resistance to bacterial blight, blast, and sheath blight diseases in rice. Front. Plant Sci. 2020, 11, 591457. [CrossRef] [PubMed]

54. Hsu, Y.C.; Chiu, C.H.; Yap, R.; Tseng, Y.C.; Wu, Y.P. Pyramiding bacterial blight resistance genes in Tainung82 for broad-spectrum resistance using marker-assisted selection. Int. J. Mol. Sci. 2020, 21, 1281. [CrossRef] [PubMed]

55. Cobb, J.N.; Biswas, P.S.; Platten, J.D. Back to the future: Revisiting MAS as a tool for modern plant breeding. Theor. Appl. Genet. 2019, 132, 647-667. [CrossRef] [PubMed]

56. Balachiranjeevi, C.; Bhaskar, N.S.; Abhilash, V.; Akanksha, S.; Viraktamath, B.C.; Madhav, M.S.; Hariprasad, A.S.; Laha, G.S.; Prasad, M.S.; Balachandran, S.M.; et al. Marker-assisted introgression of bacterial blight and blast resistance into DRR17B, an elite, fine-grain type maintainer line of rice. Mol. Breed. 2015, 35, 151. [CrossRef] 